\title{
Public Private Partnerships for Healthcare Delivery in India
}

\author{
B Birla, U Taneja
}

\section{Citation}

B Birla, U Taneja. Public Private Partnerships for Healthcare Delivery in India. The Internet Journal of World Health and Societal Politics. 2010 Volume 7 Number 1.

\section{DOI: $\underline{10.5580 / 18 \mathrm{c} 1}$}

\begin{abstract}
Healthcare delivery is a major concern for India and other developing nations because of the lack of infrastructure and limited resources. Often the healthcare delivery is restricted in reach and most vulnerable populations remain untouched. The ambitious health goals for the country demand the need for an alternate system, which encourage the private and non-state players to engage in partnerships with the state run public healthcare delivery institutions. The current system of India also needs to be flexible and should be able to adapt to the changing health needs as well as respond to the risks and opportunities that may come in the future. A new mechanism in the form of Public Private Partnerships (PPPs) in healthcare delivery is being encouraged by the government. Such PPPs are being viewed as social experiments which can supplement the state run health services by engaging private players. These partnerships are based on different models and share different relationships with the other state and non-state players. It is also believed that the drawbacks of private healthcare delivery can be mitigated to an extent by these PPPs. The SAP-LAP analysis of the Indian healthcare system shows that such PPPs can be successful if sustainable models are promoted. There is also a need for a clear guideline or policy in formulating PPPs as these models tend to be quite varied in nature, scope and delivery.
\end{abstract}

\section{INTRODUCTION}

In the last two decades, there has been a growing concern over the performance of the healthcare delivery system in India. In the year 2006, a mere $0.9 \%$ of the GDP was allocated to public health. As per the Government of India's (GOI) National Rural Health Mission (NHRM) Document (2005), only $10 \%$ of Indians have some form of health insurance and mostly this is inadequate. Around $40 \%$ of Indians have to borrow money or sell their assets to meet their healthcare expenses. Nearly $25 \%$ of Indians slip below the poverty line because of hospitalization due to a single bout of illness. The public healthcare delivery system, in its present state, is unable to deliver and meet the health goals of India. The GOI Report of the National Commission on Macroeconomics and Health (2005) states that the principal challenge for India is building a sustainable healthcare system. Selective, fragmented strategies and lack of resources have made the health system unaccountable, disconnected to public health goals, inadequately equipped to address people's growing expectations and inability to provide financial risk protection to the poor. According to the Organisation for Economic Co-operation and Development (OECD) Report (2004), adequate and effective delivery of public services is also central to achieving the Millennium Development Goals (MDGs) as proposed by the United Nations. At the national level for India, the MDGs have been integrated into the $10^{\text {th }}$ and $11^{\text {th }}$ Five Year Plans as well as forming an integral part of the NRHM.

A World Bank Report (2004) analyzes that even when resources are available for services such as primary healthcare, many governments have failed to reach the poor through public channels. One of the reasons is that although resources are allocated the funds often do not reach the frontline service providers or the intended beneficiaries. Also, traditional approaches tend to focus more on inputs, such as equipment, materials and salaries, regardless of varying local needs.

In recent years, the GOI has formulated a number of innovative policies and plans to address the issue of underperformance of the healthcare delivery system. It has introduced a number of reforms across different sectors, such as healthcare financing, health insurance, continuing medical education, and health information systems. Peters et al. state that India's health system is being forced to adapt to changing health conditions, new technologies, 
transformations in society and evolving roles for government and the private sectors (Peters; et al., 2003). Such flexibility in the healthcare system is important at this stage because of the complex demands, changing scenarios, and evolving healthcare needs of the people. Besides, the strategic and business needs also demand that future systems be flexible, i.e. should have the ability quickly change or respond with little or no implications in terms of resources, time, inputs or performance (Upton, 1994).

The rising cost of delivering healthcare services by the state and other partners in the health system is assuming critical importance. There is a vast vulnerable population which needs these services and despite the increasing healthcare network, still remains deprived of quality health services. The accelerated expenses on health warrant an efficient healthcare delivery system. An efficient healthcare system is one which can deliver maximum outputs by judiciously utilizing the available inputs. Making the current system robust, flexible and efficient has become a major area for deliberations for the policy makers and healthcare financers.

\section{ROLE OF DIFFERENT HEALTHCARE PROVIDERS}

The GOI's Report (2006-7) by The Task Force on Medical Education for the NHRM, states that the private sector provides $58 \%$ of the hospitals, $29 \%$ of the beds in the hospitals and $81 \%$ of the doctors. Nearly $78 \%$ of the rural and $81 \%$ of the urban population is provided medical treatment by private healthcare players. Also, according to the National Sample Survey Organisation (NSSO) $60^{\text {th }}$ Report (2004), use of public healthcare is lowest in the rural areas of the states of Bihar (up to $89 \%$ in urban and $95 \%$ in rural areas) and Uttar Pradesh. Approximately $77 \%$ of Out Patient Department (OPD) cases in rural areas and $80 \%$ in urban areas are being serviced by the private sector in the country.

Bhat suggests that one must look at other options for healthcare delivery because there are no regulations to monitor the cost and quality of the private players. Apart from these negative consequences of the private sector growth, the cost of private healthcare cannot be afforded by most people from the lower strata of society. Those who do use private services, do so at an exorbitant cost. Bhat further comments that the cost of healthcare, access and quality problems will worsen with the growth of the private sector. The public policy response to check some of the undesirable consequences of this growth is critical and should focus on strengthening the existing institutional mechanisms to protect patients, developing and implementing an appropriate regulatory framework, and strengthening the public healthcare delivery system (Bhat, 1999).

Apart from the private players, many civil society organizations (CSOs) have also entered the arena of healthcare delivery. Most often, the CSOs partner either with the government or the private players to deliver health services. There is also a partnership between the state or the public health institutions and the private organizations. Such Public Private Partnerships (PPPs) are being encouraged by governments across the globe. The United Nations Economic and Social Council (2005) report states that the fear of privatizing the healthcare services has been, to an extent, mitigated by the PPPs because of the potential advantages these partnerships offer, such as efficiency, outreach, sustainability, and quality of services. Best practices and good examples of PPPs have initiated a favourable change towards PPPs in the healthcare polices of several countries.

Widdus urges one to view PPPs as social experiments that are attempting to learn how to tackle intractable health problems in better ways (Widdus, 2001). According to Malmborg et al. most PPPs are currently poorly regulated as developing countries do not have the resources to monitor the quality of health services provided (Malmborg; et al., 2006). Buse and Waxman state that an organization should draw lessons from its own experience of partnerships and develop indicators of success (Buse; Waxman, 2001).

The GOI is acknowledging the role and contribution of PPPs in meeting the health goals of the country. Promotion of these PPPs is also important to lessen the burden on the Government in terms of providing the outreach as well as to alleviate resource constraints. Under the $10^{\text {th }}$ Five Year Plan (2002-2007), initiatives have been taken to define the role of the Government, private healthcare providers and CSOs in meeting the growing needs for healthcare services and meeting the goals of the National Health Programmes. The Planning Commission of the GOI (2007) constituted a Working Group on PPPs to improve healthcare delivery for the $11^{\text {th }}$ Five-Year Plan. The Working Group stresses the importance of formulating policies that promote the growth of PPPs and advocates for PPPS subject to their suitability at the primary, secondary and tertiary levels of healthcare delivery.

The contemporary National Health Policy (NHP) of India, 
formulated in the year 2002, and the ambitious NRHM formulated for the period 2005-2012, takes into consideration the vital role that is being played by private players and civil society organizations and recommends further partnerships. The NHP calls for participation of the private sector in primary, secondary and tertiary care in urban and rural India. It recommends suitable legislation for regulating minimum infrastructure and quality standards in clinical establishments and medical institutions. The NRHM proposes to support the development and effective implementation of regulating mechanisms for the private health sector to ensure equity, transparency and accountability in achieving public health goals.

It has been felt that encouraging business players to enter into efficient forms of healthcare delivery, PPPs would help bring disjointed public and private players on a common platform and move towards a common agenda and help ease the overburdened public healthcare system.

\section{FLEXIBLE HEALTHCARE SYSTEMS WITH A FOCUS ON PPPS}

The World Health Report 2000 (WHO 2000) identifies four vital functions which can affect the outcome of a health system. These are stewardship (governance), financing, human and physical resources, and organization and management of service delivery. To perform these functions, the healthcare system should have the ability to respond to the changing requirements and adapt effectively to fulfil these needs. This will result in a robust system which can take advantages of the opportunities, prepare for the risks and exhibit planned response to the challenges. Like any other flexible system, the health system should show anticipation, agility and adaptability. Anticipation means the ability to predict, plan and prepare for known and unknown challenges. Agility refers to the ability to rapidly respond to opportunities and threats and as well as to initiate changes for better delivery. Adaptability refers to learn from the past experiences and realize that changes are constant (Patten; et al., 2005).

To meet the current challenges of healthcare delivery, using the available resources, anticipating the future needs, opportunities and threats, strategic planning is required. One of the frameworks, called the SAP-LAP framework proposed by Sushil (2001) looks at flexible systems and is useful in such strategic planning. The SAP-LAP framework analyzes the relationship between situational analysis $(\mathrm{S})$, the stakeholders or the actors (A) and the processes $(\mathrm{P})$ that lead to key learning issues (L) followed by suggested actions (A) and depending upon the effectiveness of the actions, there can be enhanced expected performance $(\mathrm{P})$. According to Sushil, the more the freedom the actors have, the more adaptive and flexible the processes can be and the better the change. This is because the actors need to perform within the given situation by following certain processes. This synthesis and interaction between the different components of Situation-Actor-Process (SAP) and Learning-ActionPerformance (LAP) helps in dealing with the changing situations and brings about a more positive outcome. This improved performance can, in-turn, affect the situation, actors and processes at different levels (Sushil, 2001).

\section{APPLICATION OF THE SAP-LAP FRAMEWORK}

The PPPs bring with them a paradigm shift in the way healthcare goals are being addressed. The existing arrangement needs to change to a new synergistic framework for supporting the vast and varied healthcare needs of the country. Since the healthcare system is fast evolving, the use of SAP-LAP analysis in strategic management of healthcare delivery is helpful.

\section{SITUATIONAL ANALYSIS}

- The Indian healthcare sector, structured in three tiers (primary, secondary and tertiary), is characterized by the presence of several distinct systems of healthcare delivery such as the government, not-for-profit, charitable organizations, corporate hospitals, and smaller private clinics. There are no well defined forward or backward linkages between these players.

- The system in the current state is incapable of meeting the health goals of country and in providing adequate cover to the underserved and the poor.

- The healthcare providers work in specific domains or areas and fail to provide a continuum of healthcare services. Selective, fragmented strategies and lack of resources make the current health system ill equipped to address people's growing expectations for quality healthcare.

- Private healthcare systems are catering to the needs of people. However, such provision is expensive and unaffordable by a vast population. Health insurance is taken by a fraction of the population. Even when available, it is inadequate. 
- The priorities and agendas of the different players are disjointed. There is a need to align these as per the national health goals of the country.

- There is a need for an alternate system for healthcare delivery that supports and augments the existing system.

- The Indian government has introduced a number of reforms across different sectors, such as healthcare financing, health insurance, continuing medical education, and health information systems. PPPs are being promoted in these sectors and are emerging as a strong alternate to the public delivery mechanisms, especially in healthcare delivery. These PPPs target the population which is denied quality healthcare because of the limited reach and scope of the public health services.

\section{ACTORS}

- Government of India.

- Healthcare providers - both public and private.

- International policy influencers, such as United Nations agencies, multilateral and bilateral donors, and funding agencies.

- Doctors, nurses, and paramedical staff, engaged in actual delivery of services.

- Administrative and managerial staff.

- Patients, healthcare seekers, other indirect consumers of healthcare services, such as relatives and friends of the patients.

- A coalition of the private healthcare providers, civil society organizations, and the Government of India in the form of PPPs.

\section{PROCESSES}

- Public players, such as the state provides the basic healthcare services, through a three-tier system of primary, secondary and tertiary health services. Such services are delivered via a network of Primary Health Sub-Centres (PHSC), Primary Health Centres (PHC), Community Health Centres (CHC), district hospitals and tertiary care hospitals, and referral centres.
- Private players dominate the healthcare delivery market in India. It is the lack of public provision for health services that has resulted in the emergence of a large unregulated and urban-centric private health sector. According to the National Health Accounts Report (2009), out of the total health expenditure on health, the share of private sector was $78.05 \%$, and that of the public sector was $19.67 \%$. Additional $2.28 \%$ was contributed by different external sources.

- PPPs are modelled on different partnership mechanisms. Among the types and models of partnership, Venkat Raman et al. state that the most common are contracting (contracting-out and contracting-in); franchising; social marketing; joint ventures; subsidies and tax incentives; vouchers or service purchase coupons; hospital autonomy; build, operate, and transfer; philanthropic contributions; health co-operatives; grants-in-aid; capacity-building; leasing; and social health insurance. Different types of PPP models are suitable in different circumstances and for meeting specific requirements. Out of the above, the contracting model is the most popular form of PPP arrangement (Venkat Raman; et al., 2006)

- A PPP unit can have different types of relationships with the other healthcare providers. According to Zafar Ullah et al. a PPP unit can have parallel activities, which means that the healthcare providers coexist but work in isolation and without any synergy or contact with each other. The activities could be competitive, and the PPP and other healthcare providers may perform similar activities and cater to the same population, providing greater choices for the users. The other form of relationship can be complementary where one provider complements the activities of the other, including enhancements in geographical reach of services, population coverage, or range of services. The contractual relationship is one of the most common forms where one provider contracts with the other to provide services, at a cost. The healthcare providers may share a collaborative relationship, and one provider collaborates with each other to meet a specific objective sharing activities and goals (Zafar Ullah; et al., 2006). 


\section{LEARNING ISSUES}

- The PPPs are assuming importance in the area of healthcare delivery. Such partnerships can expand the reach of healthcare services and supplement the existing mechanisms.

- The Government of India as well as international bodies have issued broad guidelines for the formation of these partnerships. But there are no guidelines or established frameworks defined for measuring the impact or efficiency of these partnerships.

- There are several models of PPPs, which operate on different partnership mechanisms that govern the relationship between the other state and nonstate partners (other private service providers). Though not all PPPs have profit motives, yet for a sustainable PPP model, it is important that these PPPs operate at the most efficient levels.

- There is a need to identify different factors which can contribute towards making such partnerships successful and integrate the country's healthcare agenda into the priorities of the public and private players.

\section{SUGGESTED ACTIONS}

- PPPs should be taken as innovative alliances which function on the joint parameters of risks and rewards with appropriate resource allocation to meet the needs of public health delivery.

- A strategic framework of healthcare delivery through these partnerships needs to be developed.

This framework should take into account the varied health needs of the country.

- It is important to clearly identify the input and output factors that ultimately affect the expected outcomes of the PPP venture. Once these factors are identified, they can be used to develop PPP models that are efficient and provide cost-effective quality health services.

\section{EXPECTED PERFORMANCE}

Focusing on the crucial factors that govern the efficiency of PPPs can help enhance their effectiveness and success. This can further help in enhancing positive health outcomes for the population catered by such PPPs.

A holistic approach through PPPs will help develop healthcare delivery mechanisms that have inclusive strategies to improve the quality and reach of healthcare as well as ensure the sustainability of these partnerships.

\section{CONCLUSION}

The SAP-LAP analysis shows that the current healthcare infrastructure is incapable of meeting health goals and is largely dominated by disjointed and unconnected strategies, and lack of resources. There is limited reach and scope of public health services with players working in isolation. There is an urgent need to develop an alternate system for healthcare delivery in the form of PPPs, which the GOI is also encouraging. PPPs should be considered as innovative joint alliances, functioning on joint parameters of risks and rewards. Balance should be maintained between the healthcare needs of the public and the interests of the private players.

There are several other parameters that may influence the effectiveness of the PPPs. The more efficient the PPP model, the more the chances of sustainability of the model. Many such models may not be sustainable, and they fail not because of the flaw in the model, but more so, because of lack of operational efficiency. Since these models are based on partnerships, each partner must have adequate representation and say in the process. Equally important are the key stakeholders in the form of the general population, whether diseased or not. The healthcare needs are different for different situations and different target populations. It may be difficult to propose one single model as one model may not fit in each situation. However, in the absence of a clear guideline or policy in formulating PPPs, these models tend to be quite varied in nature, scope and delivery. A PPP framework can provide a sustainable and mutually advantageous collaborative arrangement to increase reach and improve the quality of healthcare delivered. 


\section{Figure 1}

Annexure 1: SAP-LAP Analysis

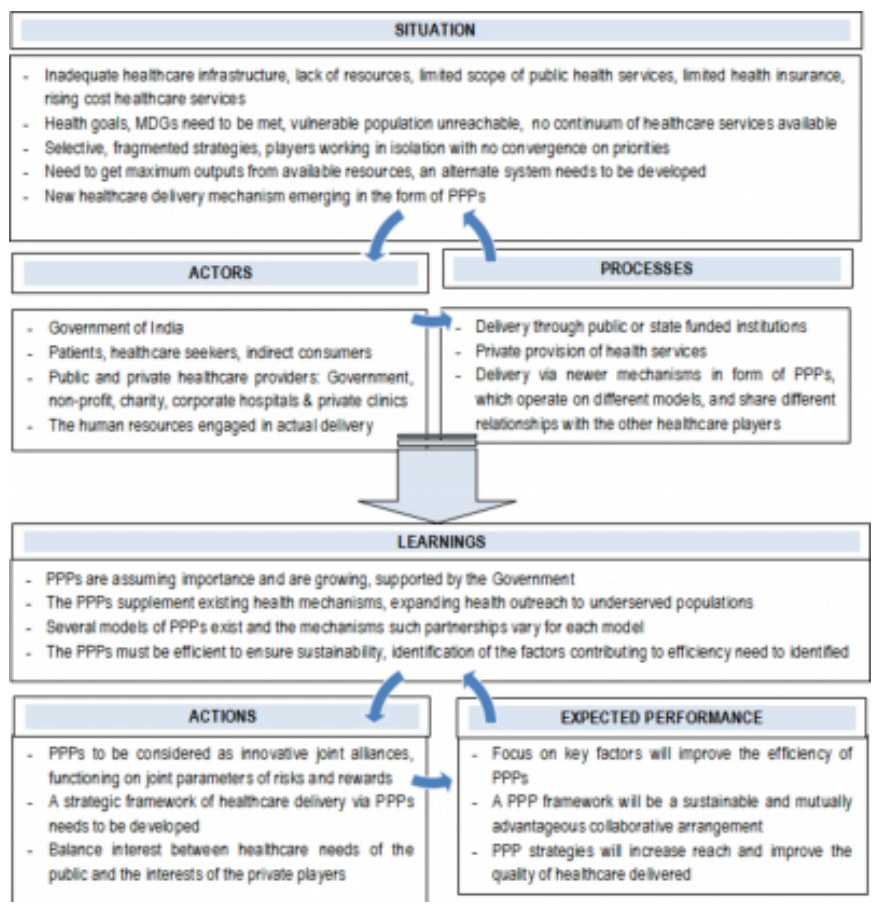

\section{References}

1. Bhat, R. (1999): Characteristics of private medical practice in India: a provider perspective. Health Policy and Planning 14, pp. 26-37.

2. Buse, K.; Waxman, A. (2001): Public-private health partnerships: a strategy for WHO. Bulletin of the World Health Organization 79, pp. 748-754.

3. Government of India. (2002): 10th Five Year Plan (2002-2007). Planning Commission of India.

4. Government of India. (2005): Report Of The National Commission On Macroeconomics And Health, National Commission On Macroeconomics And Health. Ministry Of Health \& Family Welfare.

5. Government of India. (2005): Ministry of Health and Family Welfare, The 10th Five Year Plan, Mission Document - National Rural Health Mission (2005-2012).

6. Government of India. (2007): Report On

Recommendation Of Task Force On Public Private

Partnership For The 11th Plan (2007-2012). Planning Commission of India.

7. Government of India. (2008): Ministry of Health and Family Welfare website http://www.mohfw.nic.in.

8. Government of India. (2008): Report of The Task Force on Medical Education for the National Rural Health Mission, Ministry of Health and Family Welfare.

9. Government of India. (2009): National Health Accounts
India Report, Ministry of Health and Family Welfare, Government of India. 10. Malmborg, R.; Mann, G.; Thomson, R.; Squire, BS. (2006): Can public-private collaboration promote tuberculosis case detection amongst the poor and vulnerable? Bulletin of the World Health Organization 84, pp. 752-758.

11. National Sample Survey Organization (NSSO) 60th Report. (2004): Report No. 507: Morbidity, Health Care and the Condition of the Aged, Jan - June, 2004.

12. Organisation for Economic Co-operation and

Development. (2004): A Global Plan to Achieve the MDGs, Draft report for discussion at the OECD-DAC High-level Consultation on the UN Millennium Project, 8-9 July, 2004 13. Patten, K.; Whitworth, B.; et al. (2005): Leading IT Flexibility: Anticipation, Agility and Adaptability, Americas Conference on Information Systems, August 11-14, Omaha, Nebraska, USA.

14. Peters, DH.; Rao, KS.; Fryatt, R. (2003): Lumping and splitting: the health policy agenda in India. Health Policy and Planning 18(3), pp. 249-260.

15. Steering Committee for the Review of Commonwealth/State Service Provision. (1997): Data Envelopment Analysis: A technique for measuring the efficiency of government service delivery. AGPS, Canberra, Australia.

16. Sushil (2001): SAP-LAP Framework. Global Journal of Flexible Systems Management 2 (1), pp. 51-55.

17. The World Health Organization (2000): World Health Report 2000: Health Systems- Improving Performance, Geneva.

18. The World Bank. (2002): India: Raising the Sights Better Health Systems for India's Poor: Findings, Analysis, and Options, Health, Nutrition, and Population Series.

19. The World Bank. (2004): World Development Report 2004: Making Services Work for Poor People.

20. United Nations Economic and Social Council. (2005):

Public-Private Partnerships (PPPs) For Service Delivery:

Water Supply and Sanitation. Third meeting of the

Committee on Human Development and Civil Society, 4-6

May, Addis Ababa, Ethiopia.

21. Upton, DM. (1994) The management of manufacturing flexibility, California Management Review, 36, 2.

22. Venkat Raman, A.; Björkman, JW. (2006):

Public/Private Partnership in Health Care Services in India, Health Administrator, Volume XXI, pp 62-77.

23. Widdus, R. (2001): Public-private partnerships for health: their main targets, their diversity, and their future directions. Bulletin of the World Health Organization 79, pp. $713-72$.

24. Widdus, R. (2003): Public-private partnerships for health require thoughtful evaluation. Bulletin of the World Health Organization 81 (4), pp. 235.

25. Zafar Ullah, AN.; Newell, JN.; Ahmed, JU.; et al. (2006); Government-NGO collaboration: the case of tuberculosis control in Bangladesh. Health Policy and Planning 21, pp. 143-155. 


\section{Author Information}

Bharti Birla

Research Scholar, University School of Management Studies, GGS Indraprastha University

Udita Taneja, Ph.D.

Associate Professor, University School of Management Studies, GGS Indraprastha University 